\title{
The value of prophylactic cranial irradiation in limited-stage small cell lung cancer: should it always be recommended?
}

\author{
Minji Koh', Si Yeol Song ${ }^{1}$, Ji Hwan Jo ${ }^{1}$, Geumju Park², Jae Won Park ${ }^{3}$, Su Ssan Kim, Eun Kyung Choi \\ 'Department of Radiation Oncology, Asan Medical Center, University of Ulsan College of Medicine, Seoul, Korea \\ ${ }^{2}$ Department of Radiation Oncology, Inje University Haeundae Paik Hospital, Busan, Korea \\ ${ }^{3}$ Department of Radiation Oncology, Yeungnam University Medical Center, Daegu, Korea
}

Purpose: Prophylactic cranial irradiation (PCI) is a standard treatment for limited-stage small cell lung cancer (LS-SCLC) showing a response to initial treatment, but many patients do not receive $\mathrm{PCl}$ due to comorbidities or refusal. This study aims to define the patient group for whom $\mathrm{PCl}$ can be omitted with minimal risk.

Materials and Methods: Patients with LS-SCLC who underwent radiotherapy with curative aim at our institution between January 2004 and December 2015 were retrospectively reviewed. Patients who did not receive PCI were evaluated for brain metastasis-free survival (BMFS), progression-free survival (PFS), overall survival (OS), and prognostic factors for survival, and treatment outcomes were compared with a patient cohort who received PCI.

Results: A total of 350 patients achieved a response following thoracic radiotherapy, and 190 of these patients did not receive PCI. Stage I-II and a complete response (CR) to initial therapy were good prognostic factors for BMFS and OS on univariate analysis. Patients with both stage I-II and a CR who declined PCI showed comparable 2-year BMFS to those who received PCI (92\% vs. 89\%). In patients who achieved $\mathrm{CR}, \mathrm{PCl}$ did not significantly improve OS or PFS.

Conclusion: There should be less concern about omitting PCl in patients with comorbidities if they have stage I-II or a CR, with brain metastasis control being comparable to those patients who receive $\mathrm{PCl}$.

Keywords: Small cell lung carcinoma, Radiotherapy, Prophylactic cranial irradiation, PCl, Brain, Complete remission

\section{Introduction}

Small cell lung cancer (SCLC) is an aggressive variant of lung cancer forming approximately 13\% of lung cancer cases. Limited-stage SCLC (LS-SCLC), which is a candidate for definitive radiotherapy combined with chemotherapy, accounts for $37 \%-40 \%$ of SCLC cases at the time of diagnosis $[1,2]$. Although SCLC typically shows a good response to chemoradiotherapy, the prognosis for LS-SCLC remains dismal with a median survival time of around 13 months [1]. The central nervous system (CNS) is a common site of distant failure with the 2 year brain metastasis rate being above $50 \%$ for patients who do not receive prophylactic cranial irradiation (PCI) [3].

$\mathrm{PCl}$ for LS-SCLC patients showing a good response to initial therapy is known to reduce the risk of brain metastasis

Received 12 June 2019, Revised 18 July 2019, Accepted 22 July 2019.

Correspondence: Si Yeol Song, Department of Radiation Oncology, Asan Medical Center, University of Ulsan College of Medicine, 88, Olympic-ro 43-gil, Songpa-gu, Seoul 05505, Korea. Tel: +82-2-3010-4431, Fax: +82-2-3010-6950, E-mail: coocoori@amc.seoul.kr (https://orcid.org/0000-0003-0090-8345)

(c) This is an Open Access article distributed under the terms of the Creative Commons Attribution Non-Commercial License (http://creativecommons.org/ licenses/by-nc/4.0/) which permits unrestricted non-commercial use, distribution, and reproduction in any medium, provided the original work is properly cited.

www.e-roj.org 
and improve overall survival (OS) $[4,5]$. The recent National Comprehensive Cancer Network (NCCN) guidelines, version 2.2018 for SCLC recommend PCI for LS-SCLC patients showing a complete response (CR) or partial response (PR), excluding those with poor performance status or impaired neurocognitive function [6]. Although consistent data on neurocognitive decline associated with the generally used $\mathrm{PCl}$ dose of $25 \mathrm{~Gy}$ is limited [7-9], the risk of neurocognitive dysfunction after $\mathrm{PCl}$ is a main concern associated with the decision of whether or not to apply PCI. Around 40\% of patients with $\mathrm{SS}$-SCLC are reported to decline $\mathrm{PCl}$ because of neurotoxicity concerns $[10,11]$.

To our knowledge, only a few reports on the treatment outcomes of patients who did not receive $\mathrm{PCl}$ have been published according to current medical treatments $[12,13]$. An understanding of the treatment outcomes and prognostic factors may be helpful in deciding whether or not to apply $\mathrm{PCl}$ to patients with comorbidity, despite a good response to initial therapy. Therefore, we retrospectively analyzed the survival outcomes and prognostic factors in LS-SCLC patients who did not receive $\mathrm{PCl}$ in attempt to identify the patient group for whom not administering $\mathrm{PCl}$ would cause minimal concern.

\section{Materials and Methods}

\section{Patient enrollment}

We retrospectively reviewed patients with LS-SCLC who received radiotherapy with a curative aim at our institution between January 2004 and December 2015. All patients were diagnosed pathologically and underwent a standardized evaluation including routine laboratory tests, chest computed tomography (CT), and bone scan or positron emission tomography/computed tomography (PET/CT). Contrastenhanced magnetic resonance imaging (MRI) or CT of the brain was performed before initiation of treatment to confirm the absence of brain metastasis. Staging was performed according to the tumor-node-metastasis (TNM) classification of the American Joint Committee on Cancer 7th edition, and a two-stage staging based on the NCCN guidelines, version 2.2018 [6]. Therapeutic response was evaluated with chest CT using the Response Evaluation Criteria in Solid Tumors (RECIST) guidelines, version 1.1. A total of 372 LS-SCLC patients received thoracic radiotherapy, and 94.1\% (350/372) achieved a CR or PR following initial therapy. Of these patients, 57\% (190/350) did not receive $\mathrm{PCl}$ despite a response following thoracic radiotherapy, and this patient group was evaluated to determine the prognostic factors for survival outcomes.
Additionally, the survival was compared between patients who underwent $\mathrm{PCl}$ and those who did not. This study was approved by the Institutional Review Board of the Asan Medical Center (No. 2019-0772), and the requirement for informed consent was waived because of the retrospective nature of the study.

\section{Treatment}

Thoracic radiotherapy was planned using either threedimensional conformal radiotherapy (3D-CRT; 183/190, $96.3 \%)$, intensity-modulated radiotherapy (3/190, 1.6\%), or stereotactic body radiotherapy for the small primary tumor combined with 3D-CRT for mediastinal nodes (4/190, 2.1\%). Treatment planning was performed using CT simulation, with the gross tumor volume (GTV) including the primary tumor and involved lymph nodes. A clinical target volume (CTV) was delineated in the case of clinically suspicious lesions, and the planning target volume included the GTV or CTV with a 5-10 $\mathrm{mm}$ margin. Conventional fractionated radiotherapy to a total of 50-66 Gy (median, 52.5 Gy) with 2.0-2.2 Gy per fraction (median, 2.1 Gy per fraction) was given within 5-7 weeks. Chemotherapy mainly consisted of an etoposide and cisplatin regimen, and was delivered every 3 weeks as a cycle. Dose adjustment or replacement of the anticancer agent by carboplatin or irinotecan was considered, depending on patients' medical or general condition. Chemotherapy and thoracic radiotherapy were conducted either concurrently or sequentially, and when initial chemotherapy administered with the thoracic radiotherapy it was considered as early concurrent chemoradiotherapy (CCRT). The therapeutic effect of the initial treatment was evaluated using contrast-enhanced chest CT before consideration of $\mathrm{PCl}$, and routine blood tests and chest CTs were performed every 3-6 months. MRI or CT of the brain was not routinely performed during the follow-up period, unless the patients complained of symptoms suspicious of brain metastasis.

\section{Statistical analysis}

Progression-free survival (PFS) and brain metastasis-free survival (BMFS) were defined as the period between the start date of any anticancer treatment and the date of recurrence confirmed by radiographic study. OS was defined as the time from initiation of anticancer treatment to death. The KaplanMeier method was used to analyze survival, and differences in survival times were evaluated using the log-rank test. The t-test and chi-square test were used to evaluate differences in related factors between patients who underwent $\mathrm{PCl}$ and 
Table 1. Patients' characteristics

\begin{tabular}{|c|c|c|c|c|}
\hline & $\begin{array}{c}\text { No PCl } \\
(57 \%, n=190)\end{array}$ & $\begin{array}{c}\mathrm{PCl} \\
(43 \%, n=160)\end{array}$ & $\begin{array}{l}\text { All patients } \\
(n=350)\end{array}$ & $p$-value \\
\hline Age (yr) & $64(41-83)$ & $59(35-75)$ & $61(32-83)$ & $<0.001$ \\
\hline Gender & & & & 0.313 \\
\hline Male & 165 (86.8) & 145 (90.6) & 310 (88.6) & \\
\hline Female & 25 (13.2) & $15(9.4)$ & $40(11.4)$ & \\
\hline ECOG performance status & & & & 0.197 \\
\hline $0-1$ & $178(93.7)$ & $154(96.2)$ & 332 (94.8) & \\
\hline 2 & $11(5.8)$ & $5(3.1)$ & $16(4.6)$ & \\
\hline 3 & $1(0.5)$ & $1(0.6)$ & $2(0.6)$ & \\
\hline Smoking history & & & & 0.188 \\
\hline No & $27(14.2)$ & $15(9.4)$ & $42(12.0)$ & \\
\hline Yes & 163 (85.8) & $145(90.6)$ & 308 (88.0) & \\
\hline TNM stage & & & & 0.084 \\
\hline I & $8(4.2)$ & $2(1.3)$ & $10(2.9)$ & \\
\hline II & $18(9.5)$ & $24(15.0)$ & $42(12.0)$ & \\
\hline III & 164 (86.3) & 134 (83.8) & $298(85.1)$ & \\
\hline Timing of thoracic RT & & & & $<0.001$ \\
\hline Early CCRT & $57(30.0)$ & $71(44.4)$ & $128(36.6)$ & \\
\hline Late CCRT & $73(38.4)$ & $75(46.9)$ & $148(42.3)$ & \\
\hline Sequential RT & $59(31.1)$ & $14(8.8)$ & $73(20.9)$ & \\
\hline RT alone & $1(0.5)$ & $0(0.0)$ & $1(0.3)$ & \\
\hline Response to thoracic RT & & & & $<0.001$ \\
\hline $\mathrm{CR}$ & $53(27.9)$ & $101(63.1)$ & $154(44.0)$ & \\
\hline$P R$ & $137(72.1)$ & $59(36.9)$ & 196 (56.0) & \\
\hline
\end{tabular}

Values are presented as median (range) or number (\%).

$\mathrm{PCl}$, prophylactic cranial irradiation; ECOG, Eastern Cooperative Oncology Group; RT, radiotherapy; CCRT, concurrent chemoradiotherapy; $\mathrm{CR}$, complete response; $\mathrm{PR}$, partial response.

those who did not. Univariate analysis and multivariate Cox regression analysis were performed to evaluate the influence of risk factors on survival outcomes. A p-value less than 0.05 was considered statistically significant. All statistical analysis was conducted with SPSS version 22.0 for Windows (IBM, Armonk, NY, USA).

\section{Results}

Three-hundred and fifty patients achieved either a PR or CR after radiotherapy for LS-SCLC. Among these patients, 190 (165 men, 25 women) did not receive $\mathrm{PCl}$ and were followed-up for a median period of 15 months (range, 2 to 129 months). The clinical characteristics of these patients are summarized in Table 1. Compared with the patients who received $\mathrm{PCl}$, those who did not receive $\mathrm{PCl}$ were significantly older, older underwentless CCRT, and showed less response after initial thoracic radiotherapy. All patients received chemotherapy concurrently or sequentially, except one patient who was treated with radiotherapy alone because of underlying endstage renal disease. The median number of chemotherapy cycles was 4 (range, 1 to 13 cycles). Fifty-nine of the patients who did not undergo $\mathrm{PCl}(31.1 \%)$ received sequential radiotherapy compared with 14 patients (8.8\%) with $\mathrm{PCl}$ ( $\mathrm{p}<$ 0.01). Most of the patients $(164 / 190,86.3 \%)$ were clinical stage III with there being no significant difference in the distribution of clinical stages between those who received $\mathrm{PCl}$ and those who did not.

The 2-year OS, PFS, and BMFS rates of the patients without $\mathrm{PCl}$ were $38.2 \%, 25.2 \%$, and $65.2 \%$, respectively. Table 2 shows the prognostic factors for survival according to the univariate analysis. Stage $I-I I(p=0.025)$ and achievement of a CR ( $p<0.01)$ were good prognostic factors for OS. The BMFS rate was also significantly related to TNM stage ( $p=$ $0.034)$ and response to thoracic radiotherapy $(p=0.038)$. The 2-year BMFS rates of the patients with stage $I-I I$ and a CR 
Table 2. Prognostic factors for survival in patients without $\mathrm{PCl}$ (univariate analysis)

\begin{tabular}{|c|c|c|c|c|c|c|c|}
\hline & $\begin{array}{l}\text { No. of } \\
\text { patients }\end{array}$ & $\begin{array}{c}2-y r \text { OS } \\
(\%)\end{array}$ & $p$-value & $\begin{array}{c}2-y r \text { PFS } \\
(\%)\end{array}$ & p-value & $\begin{array}{c}2-y r \text { BMFS } \\
(\%)\end{array}$ & $p$-value \\
\hline Age (yr) & & & 0.082 & & 0.782 & & 0.581 \\
\hline$<65$ & 105 & 41.6 & & 24.9 & & 63.9 & \\
\hline$\geq 65$ & 85 & 41.6 & & 25.6 & & 67.1 & \\
\hline Gender & & & 0.831 & & 0.345 & & 0.722 \\
\hline Male & 165 & 40.5 & & 26.5 & & 63.7 & \\
\hline Female & 25 & 36.0 & & 13.5 & & 74.5 & \\
\hline ECOG performance status & & & 0.255 & & 0.289 & & 0.264 \\
\hline $0-1$ & 178 & 38.5 & & 26.2 & & 65.3 & \\
\hline $2-3$ & 12 & 33.3 & & 10.4 & & 63.6 & \\
\hline Smoking & & & 0.872 & & 0.398 & & 0.837 \\
\hline No & 27 & 33.3 & & 20.5 & & 78.9 & \\
\hline Yes & 163 & 39.0 & & 25.9 & & 62.9 & \\
\hline TNM stage & & & 0.025 & & 0.090 & & 0.034 \\
\hline |-|| & 26 & 57.7 & & 42.6 & & 79.7 & \\
\hline III & 164 & 35.1 & & 22.3 & & 62.6 & \\
\hline Timing of thoracic RT & & & 0.070 & & 0.374 & & 0.939 \\
\hline Early CCRT & 57 & 41.6 & & 29.2 & & 60.4 & \\
\hline Late CCRT & 73 & 42.3 & & 27.9 & & 68.9 & \\
\hline Sequential RT & 59 & 30.5 & & 18.2 & & 63.8 & \\
\hline Response to thoracic RT & & & $<0.001$ & & $<0.001$ & & 0.038 \\
\hline $\mathrm{CR}$ & 53 & 66.0 & & 48.8 & & 72.4 & \\
\hline$P R$ & 137 & 27.3 & & 13.4 & & 60.3 & \\
\hline
\end{tabular}

PCl, prophylactic cranial irradiation; OS, overall survival; BMFS, brain metastasis-free survival; PFS, progression-free survival; ECOG, Eastern Cooperative Oncology Group; RT, radiotherapy; CCRT, concurrent chemoradiotherapy; CR, complete response; PR, partial response.
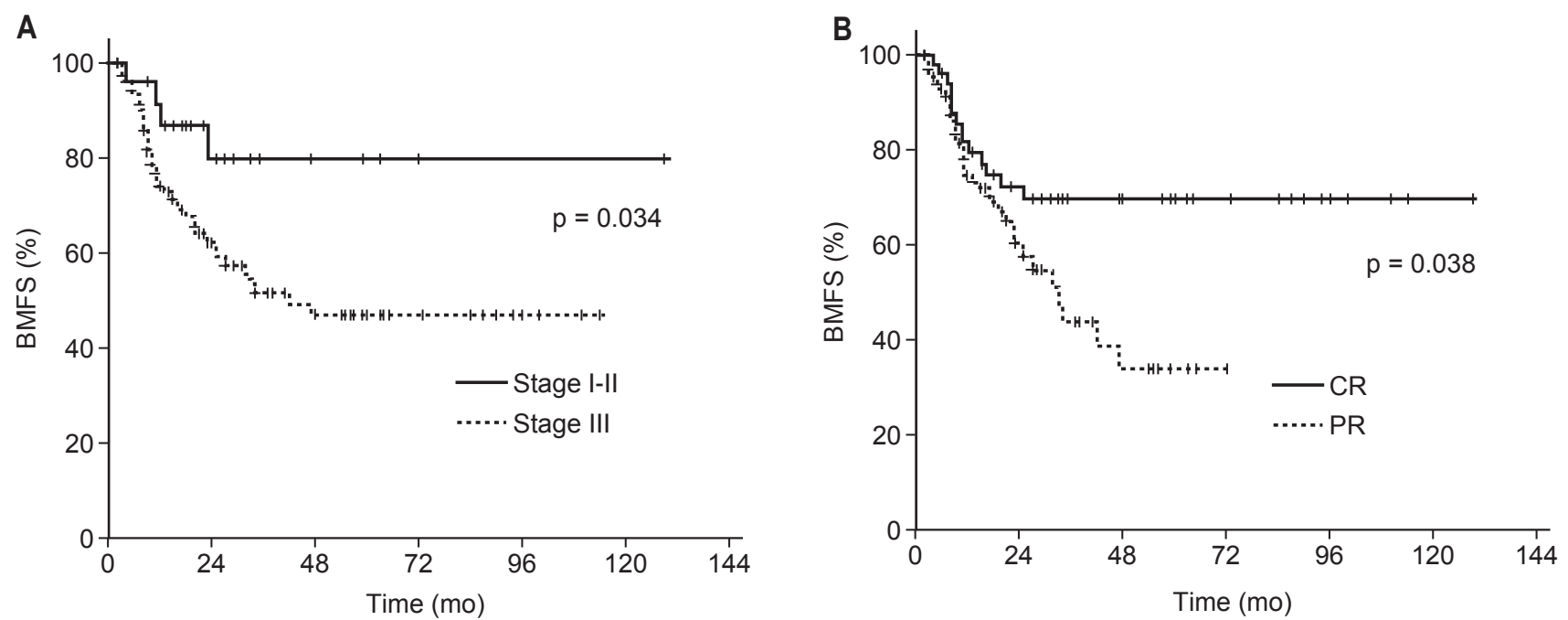

Fig. 1. Brain metastasis-free survival (BMFS) of no prophylactic cranial irradiation patients according to (A) TNM stage and (B) response to thoracic radiotherapy. CR, complete response; PR, partial response.

were $79.7 \%$ and $72.4 \%$, respectively (Fig. 1). The patients' age at the time of diagnosis showed a marginal relationship with
OS $(p=0.082)$, as did the timing of thoracic radiotherapy ( $p$ $=0.070$ ). Response to thoracic radiotherapy was a statistically 


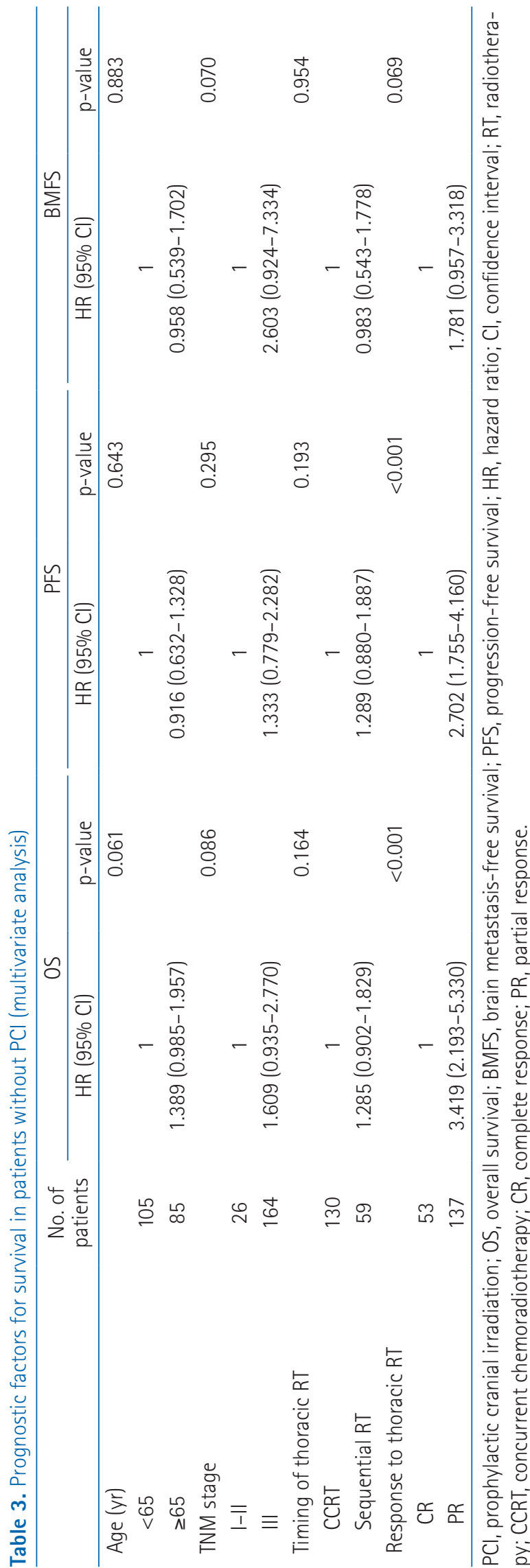

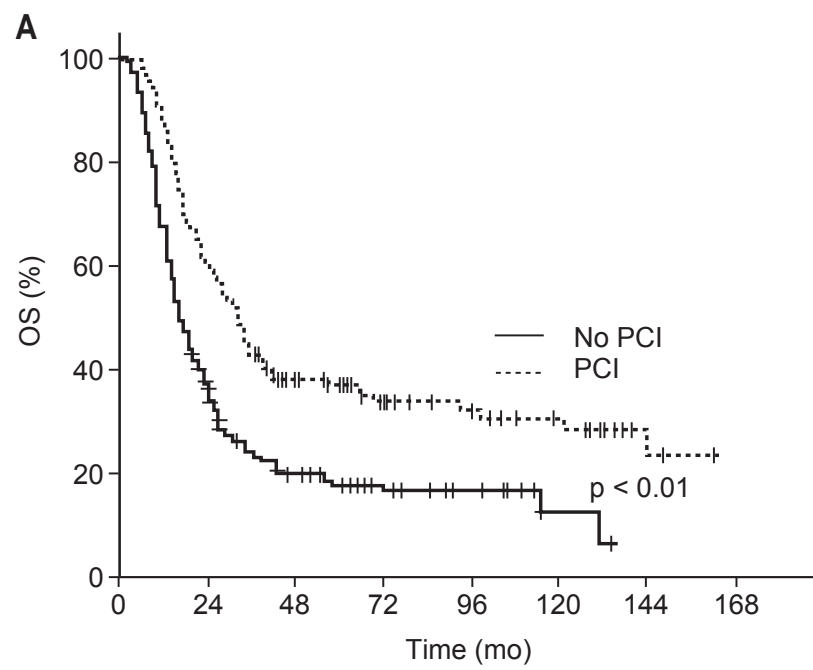
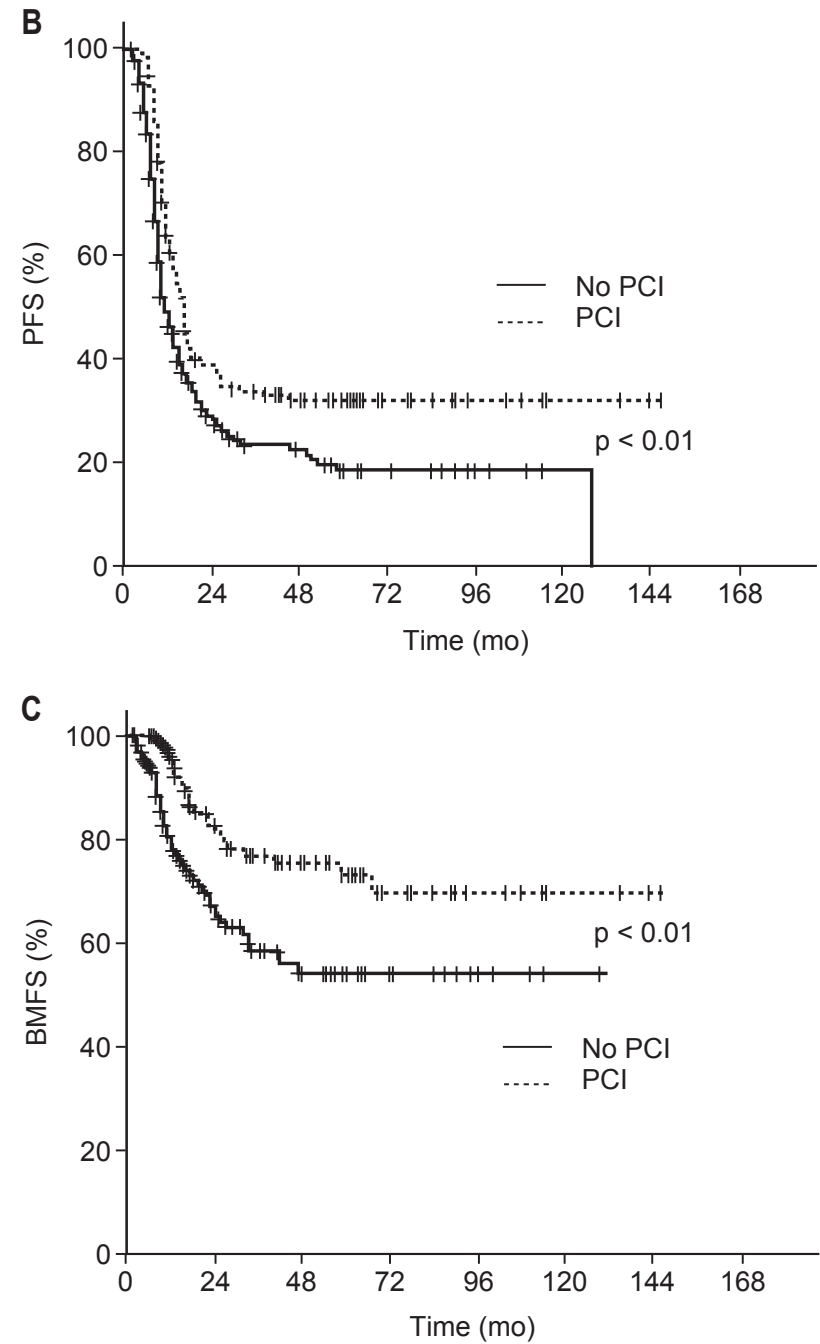

Fig. 2. Survival and recurrence in patients who received prophylactic cranial irradiation $(\mathrm{PCI})$ and those who did not: (A) overall survival (OS), (B) progression-free survival (PFS), and (C) brain metastasis-free survival (BMFS). 

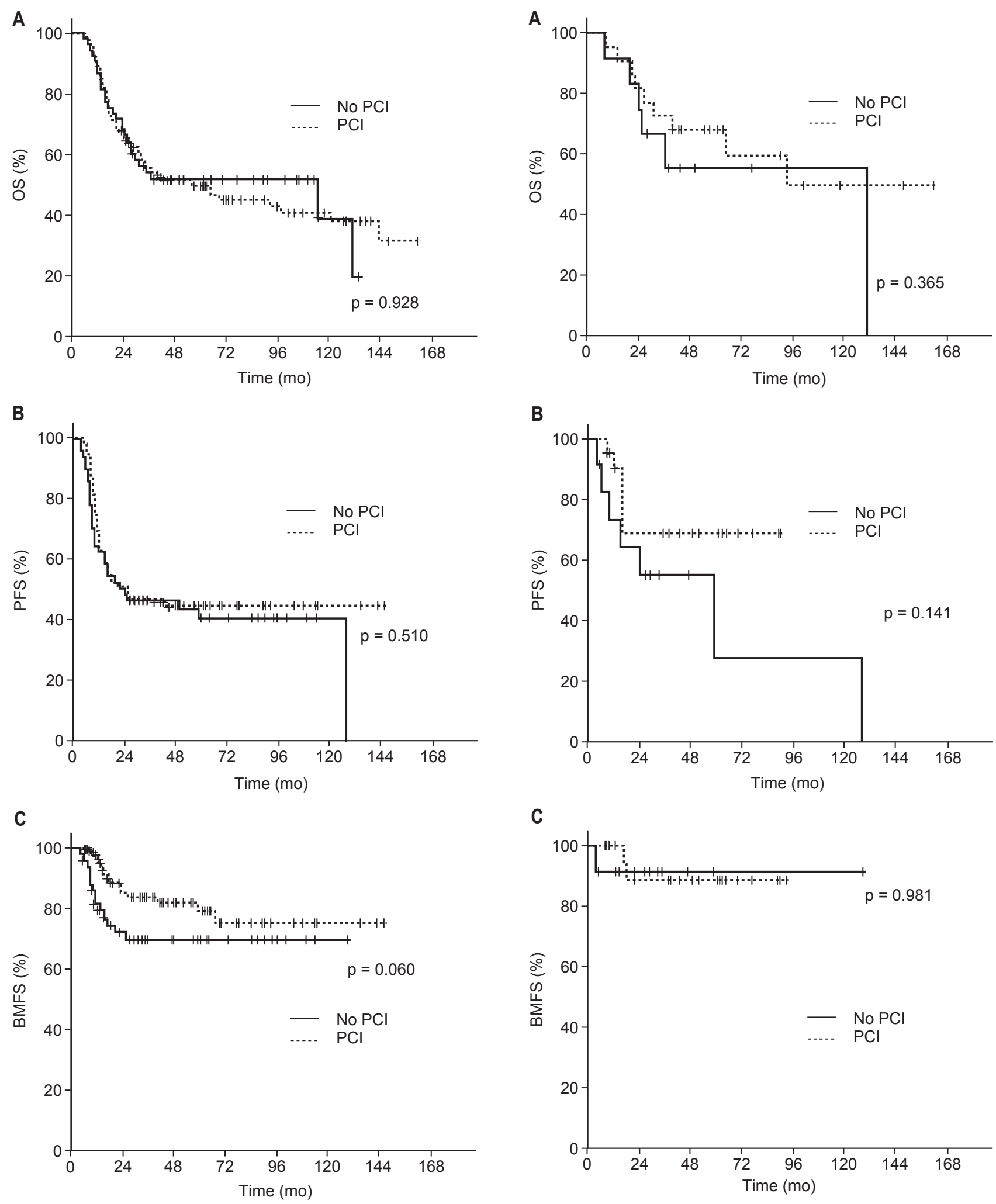

Fig. 3. Survival and recurrence in patients showing a complete response according to whether they received prophylactic cranial irradiation (PCI) or not: (A) overall survival (OS), (B) progressionfree survival (PFS), and (C) brain metastasis-free survival (BMFS). 
Table 4. Survival outcomes in the No-PCl group with stage I-II and a CR in comparison with the PCl group

\begin{tabular}{lcccc}
\hline & No. of patients & 2-yr OS (\%) & 2-yr PFS (\%) & 2-yr BMFS (\%) \\
\hline No PCl & 190 & 36.1 & 28.9 & 67.1 \\
Stage I-II & 26 & 57.7 & 42.6 & 79.7 \\
CR & 53 & 66.0 & 48.8 & 72.4 \\
Both stage I-II and CR & 12 & 75.0 & 55.0 & 91.7 \\
PCl & 160 & 59.3 & 39.0 & 82.4 \\
\hline
\end{tabular}

$\mathrm{PCl}$, prophylactic cranial irradiation; CR, complete response; OS, overall survival; BMFS, brain metastasis-free survival; PFS, progression-free survival.

significant prognostic factor ( $p<0.01)$ for PFS, while the TNM stage showed a marginal relationship $(p=0.090)$. The results of the multivariate analysis are described in Table 3. Achievement of a CR was a positive prognostic factor for OS and PFS $(p<0.01)$, and showed a marginal relationship with BMFS ( $p=0.069)$. Stage I or II disease, rather than stage III, showed a tendency toward improved BMFS, although this was not statistically significant $(p=0.070)$.

Fig. 2 depicts the survival outcomes of those who did not receive $\mathrm{PCl}$ in comparison with those who did. The OS, PFS, and BMFS rates were significantly lower in those who did not receive $\mathrm{PCI}(p<0.01)$. Additionally, a subgroup analysis conducted on the patient group who achieved a $C R(n=$ 154) following thoracic radiotherapy (Fig. 3) showed that PCl marginally improved BMFS in this patient group $(p=0.060)$, but had no significant benefit on OS or PFS. A subgroup of the patient with both CR and stage I-II $(n=34)$ was analyzed, and there was no significant difference on OS, PFS, and BMFS (Fig. 4).

The survival rate of the patient group with stage I-II, $C R$, and both stage $\mathrm{I}-\mathrm{II}$ and a $\mathrm{CR}$ who did not receive $\mathrm{PCl}$ is described in Table 4 in comparison with that of the group who did receive $\mathrm{PCl}$. The 2-year BMFS rates of $72 \%-80 \%$ in the patient group with stage I-II or a CR who did not receive PCI were little different to those of the patient groups who did receive $\mathrm{PCI}$ (2-year BMFS, 82.4\%). The 2-year OS and PFS rates of the no-PCl group with favorable prognostic factors were also comparable to the outcomes of the patients who received $\mathrm{PCl}$. Although the number of the patients in the analysis was relatively small, the BMFS, OS, and PFS rates of the no- $\mathrm{PCl}$ group with both stage I-II and a CR were favorable compared to the outcomes of the patients who did receive $\mathrm{PCl}$.

\section{Discussion and Conclusion}

For LS-SCLC patients, chemotherapy with etoposide and cisplatin together with thoracic radiotherapy is the standard treatment, which is then followed by $\mathrm{PCl}$ for patients with a response, irrespective of other indications except those of poor performance status and neurocognitive dysfunction [6]. The positive role of $\mathrm{PCl}$ has been identified in several randomized trials. A meta-analysis of seven randomized trials with a total of 987 mainly LS-SCLC patients $(847 / 987,85 \%)$ reported improvements in $O S$ and disease-free survival in those who gained a CR [5]. However, in real clinical practice, $\mathrm{PCl}$ is not administered to all eligible patients due to concerns over neurocognitive toxicity or combined comorbidity. A retrospective study on $\mathrm{PCl}$ utilization reported that $39 \%$ of patients did not receive $\mathrm{PCl}, 38 \%$ of whom declined it mainly because of concerns about its toxicity [10]. Another retrospective study on 208 eligible patients reported a comparable result, showing that $45 \%$ of the patients declined $\mathrm{PCl}$, with the major reasons for omission being patient refusal due to concern about its toxicity (38\%) and oncologists' decisions that patients were medically unfit to receive $\mathrm{PCl}$ (33\%) [11]. In our institution, 57\% of the LS-SCLC patients with a response did not receive $\mathrm{PCl}$, although there were insufficient records to allow us to report on the reasons for $\mathrm{PCl}$ omission. Understanding the clinical outcomes of patients who do not receive $\mathrm{PCl}$ despite a good response to initial therapy would be helpful for clinicians making decisions on $\mathrm{PCl}$ utilization in patients with comorbidities.

There is little published information available on the survival outcomes and prognostic factors of patients who decline $\mathrm{PCl}$, in the recent clinical situations in which $\mathrm{PCl}$ is accepted as a standard treatment for LS-SCLC. A retrospective study that reported treatment outcomes of 60 LS-SCLC patients who did not receive $\mathrm{PCl}$ after a $\mathrm{CR}$ or near-CR showed that brain metastasis, performance status, and T-stage were significantly related to OS [13]. Another recent study that performed a multivariate analysis with 153 patients reported that high T-stage, high neutrophil-to-lymphocyte ratio, early thoracic 
radiotherapy, and fewer chemotherapy cycles were risk factors for brain metastasis [12]. In our patient cohort, a lower stage and better response were associated with improved BMFS and OS in the univariate analysis, although only the relationship between response to thoracic radiotherapy and OS was significant in the multivariate analysis, with the other relationships showing only non-significant tendencies.

High TNM stage is known to be a risk factor for brain metastasis and OS in LS-SCLC. Wu et al. [14] report that stage I-II patients show a lower incidence of brain metastasis than stage III patients ( $12 \%$ vs. $26 \%$ at 5 years; $p=0.020$ ), suggesting that $\mathrm{PCl}$ may play a relatively limited role in earlystage patients. Favorable survival outcomes and a low rate of brain metastasis in early-stage patients after surgical resection have been reported in several studies $[15,16]$. This relationship was also identified in our cohort of LS-SCLC patients for whom $\mathrm{PCl}$ was omitted after thoracic radiotherapy, although we found that early-stage disease had only a marginally significant influence on OS and BMFS in the multivariate analysis. However, patients with stage I or II made up only $14 \%$ of the cases in our analysis. Stage I is rarely diagnosed and is usually treated with a surgical approach. As we analyzed only those patients who received thoracic radiotherapy, only a small number of stage I patients were included in this study. As the number of patients with early-stage disease is relatively small, caution is required in the interpretation of our results, and further analysis to determine the prognostic factors of this patient group is warranted. Nevertheless, the results of this study suggest that the use of TNM staging in addition to the two-stage system may be helpful for clinical decisionmaking.

Attainment of a CR correlated with OS, BMFS, and PFS in patients who did not receive $\mathrm{PCl}$. A phase III study demonstrated that complete responders after CCRT had a more favorable prognosis [17], while a retrospective study with a heterogeneous patient cohort also reported that a CR was associated with better OS and PFS [18]. This relationship was observed in our patient cohort without $\mathrm{PCl}$, although we did not find a significant relationship between the timing of thoracic radiotherapy and survival rates, except for a tendency toward lower OS in patients treated with sequential radiotherapy rather than CCRT, which is in agreement with previous reports $[19,20]$. Advanced age is a critical factor when deciding on $\mathrm{PCl}$, and the patients who did not receive $\mathrm{PCl}$ were significantly older than those who did. Patients aged over 65 showed lower OS, although age did not independently affect BMFS or PFS in this study. On the basis of the results of this study, various factors should be considered when evaluating the prognosis of patients who decline $\mathrm{PCl}$.

The appropriateness of prescribing $\mathrm{PCl}$ to all patients with a response to initial treatment has been continuously challenged. Although previous randomized studies investigating the efficacy of $\mathrm{PCl}$ have shown a clear reduction in brain metastasis, there was relatively low improvement in OS, which was reported to improve by only about 5\% [5]. A metaanalysis by Meert et al. [4] shows that with the introduction of brain imaging assessment before $\mathrm{PCl}$, there is a lack of data supporting the general use of $\mathrm{PCl}$ in all CR situations. It should be noted that most of the studies that randomly assigned patients to undergo $\mathrm{PCl}$ or not were performed before the modern era of $\mathrm{MRI}$. A recent randomized trial with active brain $\mathrm{MRI}$ surveillance found the role of $\mathrm{PCl}$ for extensivestage SCLC to be not essential [21], which is contrary to the result of European Organisation for Research and Treatment of Cancer (EORTC) trial, which did not include CNS imaging either before randomization or during the follow-up period [22]. A recent retrospective analysis of $L S-S C L C$ reported no significant survival benefit from $\mathrm{PCl}$ in those patients who were confirmed on brain MRI to have no brain metastasis after initial treatment [23]. In this context, $\mathrm{PCl}$ may not improve survival in all LS-SCLC patients with a response, although there is not enough data to fully support this suggestion. Defining the patient group that may show no benefit from $\mathrm{PCl}$ is important, but prognostic factors other than the application of brain MRI have rarely been reported. On the basis of this study, omission of $\mathrm{PCl}$ in patients with stage I-II or a CR may be considered with reduced concern about the increased risk of brain metastasis, especially in the era of easily accessible brain MRI.

This study has several limitations, including its retrospective nature. There may be a considerable amount of selection bias because the patients who did not receive $\mathrm{PCl}$ were selected without consistent criteria being applied, and there was a lack of information in the medical records on the reasons for omission of $\mathrm{PCl}$. We briefly compared the outcomes of treatment with or without $\mathrm{PCl}$, but the findings should be interpreted cautiously because of the heterogeneity in the characteristics between the patient groups. Conducting a prospective study to identify prognostic factors in patients without $\mathrm{PCl}$ is difficult because $\mathrm{PCl}$ is generally accepted as a standard treatment for LS-SCLC showing a response. Despite these drawbacks, to the best of our knowledge, this study is the largest retrospective single-institution study to describe the outcomes and prognostic factors of patients who did not 
receive $\mathrm{PCl}$ following a response to thoracic radiotherapy.

In conclusion, stage I-II and a CR were good prognostic factors for BMFS and OS in the patient cohort who did not receive $\mathrm{PCl}$, with such patients showing comparable survival outcomes with those who did receive $\mathrm{PCl}$. In complicated clinical situations where application of $\mathrm{PCl}$ is associated with concerns over comorbidities or neurotoxicity, $\mathrm{PCl}$ omission may be considered with reduced concerns about CNS failure in patients with stage I-II and a CR.

\section{Conflict of Interest}

No potential conflict of interest relevant to this article was reported.

\section{Acknowledgments}

This research was supported by Basic Science Research Program through the National Research Foundation of Korea (NRF) funded by the Ministry of Education (No. NRF2017R1D1A1B03035167) and by a grant from the Asan Institute for Life Sciences, Seoul, Korea (No. 2018-472).

\section{References}

1. Gaspar LE, McNamara EJ, Gay EG, et al. Small-cell lung cancer: prognostic factors and changing treatment over 15 years. Clin Lung Cancer 2012;13:115-22.

2. Govindan R, Page N, Morgensztern D, et al. Changing epidemiology of small-cell lung cancer in the United States over the last 30 years: analysis of the surveillance, epidemiologic, and end results database. J Clin Oncol 2006;24:4539-44.

3. Komaki R, Cox JD, Whitson W. Risk of brain metastasis from small cell carcinoma of the lung related to length of survival and prophylactic irradiation. Cancer Treat Rep 1981;65:811-4.

4. Meert AP, Paesmans M, Berghmans T, et al. Prophylactic cranial irradiation in small cell lung cancer: a systematic review of the literature with meta-analysis. BMC Cancer 2001;1:5.

5. Auperin A, Arriagada R, Pignon JP, et al. Prophylactic cranial irradiation for patients with small-cell lung cancer in complete remission. N Engl J Med 1999;341:476-84.

6. Kalemkerian GP, Loo BW, Akerley W, et al. NCCN Guidelines Insights: small cell lung cancer, version 2.2018. J Natl Compr Canc Netw 2018;16:1171-82.

7. Gregor A, Cull A, Stephens RJ, et al. Prophylactic cranial irradiation is indicated following complete response to induction therapy in small cell lung cancer: results of a multicentre randomised trial. Eur J Cancer 1997;33:1752-8.

8. Wolfson AH, Bae K, Komaki R, et al. Primary analysis of a phase II randomized trial Radiation Therapy Oncology Group (RTOG) 0212: impact of different total doses and schedules of prophylactic cranial irradiation on chronic neurotoxicity and quality of life for patients with limited-disease small-cell lung cancer. Int J Radiat Oncol Biol Phys 2011;81:77-84.

9. Arriagada R, Le Chevalier T, Borie $F_{1}$ et al. Prophylactic cranial irradiation for patients with small-cell lung cancer in complete remission. J Natl Cancer Inst 1995;87:183-90.

10. Giuliani M, Sun $A$, Bezjak $A$, et al. Utilization of prophylactic cranial irradiation in patients with limited stage small cell lung carcinoma. Cancer 2010;116:5694-9.

11. Lok BH, Ma J, Foster $A$, et al. Factors influencing the utilization of prophylactic cranial irradiation in patients with limitedstage small cell lung cancer. Adv Radiat Oncol 2017;2:548-54.

12. Zheng $Y$, Wang $L$, Zhao W, et al. Risk factors for brain metastasis in patients with small cell lung cancer without prophylactic cranial irradiation. Strahlenther Onkol 2018;194:1152-62.

13. Sakaguchi M, Maebayashi T, Aizawa T, Ishibashi N, Saito T. Treatment outcomes of patients with small cell lung cancer without prophylactic cranial irradiation. J Thorac Dis 2016;8:2571-9.

14. Wu AJ, Gillis A, Foster $A$, et al. Patterns of failure in limitedstage small cell lung cancer: Implications of TNM stage for prophylactic cranial irradiation. Radiother Oncol 2017;125:130-5.

15. Gong L, Wang QI, Zhao L, Yuan Z, Li R, Wang P. Factors affecting the risk of brain metastasis in small cell lung cancer with surgery: is prophylactic cranial irradiation necessary for stage I-III disease? Int J Radiat Oncol Biol Phys 2013;85:196200.

16. Ogawa $S$, Horio $Y$, Yatabe $Y$, et al. Patterns of recurrence and outcome in patients with surgically resected small cell lung cancer. Int J Clin Oncol 2012;17:218-24.

17. Sun JM, Ahn YC, Choi EK, et al. Phase III trial of concurrent thoracic radiotherapy with either first- or third-cycle chemotherapy for limited-disease small-cell lung cancer. Ann Oncol 2013;24:2088-92.

18. Manapov F, Niyazi M, Gerum S, et al. Evaluation of the role of remission status in a heterogeneous limited disease small-cell lung cancer patient cohort treated with definitive chemoradiotherapy. BMC Cancer 2016;16:216.

19. Lu H, Fang L, Wang X, Cai J, Mao W. A meta-analysis of randomized controlled trials comparing early and late 
concurrent thoracic radiotherapy with etoposide and cisplatin/ carboplatin chemotherapy for limited-disease small-cell lung cancer. Mol Clin Oncol 2014;2:805-10.

20. Takada M, Fukuoka M, Kawahara M, et al. Phase III study of concurrent versus sequential thoracic radiotherapy in combination with cisplatin and etoposide for limited-stage small-cell lung cancer: results of the Japan Clinical Oncology Group Study 9104. J Clin Oncol 2002;20:3054-60.

21. Takahashi T, Yamanaka T, Seto $T$, et al. Prophylactic cranial irradiation versus observation in patients with extensive- disease small-cell lung cancer: a multicentre, randomised, open-label, phase 3 trial. Lancet Oncol 2017;18:663-71.

22. Slotman B, Faivre-Finn C, Kramer G, et al. Prophylactic cranial irradiation in extensive small-cell lung cancer. $N$ Engl J Med 2007;357:664-72.

23. Mamesaya N, Wakuda K, Omae K, et al. Efficacy of prophylactic cranial irradiation in patients with limiteddisease small-cell lung cancer who were confirmed to have no brain metastasis via magnetic resonance imaging after initial chemoradiotherapy. Oncotarget 2018;9:17664-74. 